\title{
МЕТОДИКА ПРЕДВАРИТЕЛЬНОГО ИЗУЧЕНИЯ ПОТЕНЦИАЛЬНЫХ КОНТРАГЕНТОВ С ПОМОЩЬЮ ИНТЕРНЕТ-РЕСУРСОВ
}

Аннотация. В настоящей статье, подготовленной по итогам обучения на факультативе по курсу «Управление системами безопасности бизнеса», рассматриваются методы изучения потенциальных контрагентов с использованием сети Интернет. В качестве иллюстрации к дистанционным способам получения информации о контрагентах автор методологически приводит примеры популярных схем в интернет пространстве, основанных на недостаточной информированности одной из сторон. Новизна материала состоит в том, что он ориентирован на молодежную аудиторию, активно использующую Интернет-ресурсы в ичелях бизнеса. Исходя из этого, сегодня предприятия независимо от размера должны тщательно защищать собственные коммерческие секреты и параллельно - регулярно использовать деловую разведку. В контексте данной работы будет рассматриваться информация о потенциальных контрагентах, поскольку в повседневной жизни индивидам чаще приходится сталкиваться именно с контрагентами, а не с конкурентами; помимо этого, сбор данной информации прощее систематизировать, чем мониторинг конкурентов, зачастую носящий персонализированный характер и требующий определенных отраслевых знаний и компетенциий.

Ключевые слова: контрагенты, персональные данные, интернет, социальные сети, мониторинг, моченничество, дезинформация, деловая разведка, инфобизнес, Закон об информации.

\section{Введение}

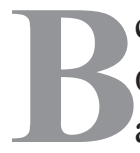
современной рыночной экономике информация становится главным активом, а также существенным экономическим ресурсом для осуществления предпринимательской деятельности. При этом само понятие «информация» является сложным и многозначным, охватывает все сферы общества и регулируется отдельными нормами права. В практическом смысле информация должна отвечать критерию полезности и может выступать и как цель, и как результат достижения экономических потребностей.

Согласно Закону об информации ${ }^{1}$ любое физическое или юридическое лицо,

\footnotetext{
${ }^{1}$ Ф3 от 27 июля 2006 г. № 149-Ф3 «Об информации,
} информационных технологиях и защите информации» являющееся обладателем обособленной информации, имеет право распоряжаться ею на праве собственности (распространять и тиражировать). В зависимости от порядка предоставления информация делится на:

- свободно распространяемую;

- предоставляемую по соглашению лиц, участвующих в соответствующих отношениях;

• подлежащую предоставлению либо распространению;

- ограниченную для распространения на территории РФ;

Для того чтобы успешно конкурировать на сегодняшнем рынке, предприятия должны регулярно вести мониторинг своих конкурентов, а особенно - контрагентов, используя для этого все возможные виды информации. 
Потребность в таких услугах привела к созданию отдельных баз данных и аналитических компаний, оказывающих услуги по сбору, хранению, обработке и систематизации информации по заданным темам. Сегодня конкуренция идет не на уровне наличия/отсутствия подразделений, занятых деловой разведкой, а на быстроту поиска и правильность анализа. Кроме того, некоторые компании сознательно предоставляют искаженную информацию информационные сообщения, отраслевые обзоры, дозируют «утечки информации» для того, чтобы дезориентировать своих конкурентов и загнать в тупик их причинно-следственную цепочку анализа действий.

Лидерами по анализу информации, находящейся в открытом доступе, являются американские фирмы «Noemic», «Verity», «IntelligentSearchSolutions». В России аналогичные услуги предоставляют $3 \mathrm{AO}$ «Скрин», «Кронос-информ», «Информбюро», «Национальное кредитное бюро» и ряд других фирм. При этом базы данных делятся на открытые (с использованием официальных источников: выписки из ЕГРЮЛ, Росстата и др.) и «серые» (информации в них гораздо больше, но она может быть устаревшей, что делает затруднительным ее применение). Классический пример «серых» баз - это диски с телефонной базой по городу, раньше их активно продавали в метрополитене и на вещевых рынках. Сейчас эти базы были расширены и перешли в online пространство.

В целом, большая часть получаемой из баз данных информации требует аналитической обработки: сравнения, обобщения, выстраивания причинно-следственных связей, а также верификации. В контексте данной работы будет рассматриваться информация о потенциальных контрагентах, поскольку в повседневной жизни индивидам чаще приходится сталкиваться именно с контрагентами, а не с конкурентами; помимо этого, сбор данной информации проще систематизировать, чем мониторинг конкурентов, зачастую носящий персонализированный характер и требующий определенных отраслевых знаний и компетенций.

\section{Способы сбора данных о потенциальных контрагентах}

Сбор данных о потенциальных контрагентах носит, в первую очередь, оборонительный характер: важно знать добропорядочность потенциального партнера для минимизации рисков имущественных и неимущественных потерь (в отличие от конкурентной разведки). Согласно гражданскому кодексу РФ ${ }^{1}$, субъект вправе:

a) в договорном порядке установить компетентный орган по разрешению споров и конфликтов;

б) обратиться к компетентным органам по защите своих нарушенных прав и интересов;

К сожалению, не всегда удается найти взаимопонимание между контрагентами с помощью нотариальной защиты, третейского разбирательства либо претензионного порядка урегулирования споров, что приводит к необходимости защищать свои интересы в судебном порядке (конституционный суд, арбитражный суд, суд общей юрисдикции).

Информация о судебных процессах по предприятиям находится в открытом доступе на сайте http://sudact.ru/

\section{Сбор данных по деятельности предприятия}

Сюда можно отнести юридические данные контрагента: полное и сокращенное название, ОГРН, ИНН, КПП, юридический и фактиче-

\footnotetext{
${ }^{1}$ Гражданский Кодекс Российской Федерации, ст. 12-16 о способах защиты гражданских прав
} 
ский адреса, расчетный счет в банке, уставный капитал, кто является учредителем компании и др. Часть данных находится в открытом доступе (регистрационный номер, сведения о выданных лицензиях, юридический адрес), а часть нужно предварительно заказывать самостоятельно или с помощью специализированных фирм (например, выписку из ЕГРЮЛ или финансовую отчетность предприятия).

Этот раздел можно назвать самым важным базовым пунктом при анализе контрагента: если выяснится, что заявленной фирмы не существует, то выполнять дальнейшие пункты по анализу сайта и деятельности предприятия нецелесообразно. Незаконное предпринимательство и сотрудничество с такими контрагентами чревато репутационными издержками и высокими рисками исчезновения контрагента.

\section{Сбор данных по месту фактической} деятельности предприятия контрагента

Если фирма имеет собственный офис/представительство, либо торговую точку, то будет полезным побывать на ней до заключения договоров или принятия иных соглашений о сотрудничестве. Иногда это бывает актуальным и в случае взаимодействия физического лица с юридическим. При этом рекомендуется вести себя спокойно, не выделяться, либо представить себя в качестве покупателя и оценить качество обслуживания. В случае, если обслуживающий персонал плохо выполняет свои прямые обязанности, не стоит давать данной фирме товар на реализацию. Стоит отметить, что в целях контроля обслуживания часто используются тайные покупатели, однако получаемая от них информация может быть слишком субъективной для составления однозначных выводов. Если планируется посещения офиса, то следует придумать правдоподобную легенду, а имидж посетителя должен быть достаточно презентабельным и уместным как по ценовому диапазону, так и по гендерному и возрастному (подросток, изучающий оптовые поставки медицинского оборудования для людей пенсионного возраста, может запомниться и показаться подозрительным в принимающей компании).

\section{Сбор данных}

\section{с помощью поисковых систем}

К особенностям данного метода следует отнести избирательность индексации, огромный объем собираемой роботами информации, в результате чего нужная информация может начать индексироваться в поисковиках лишь 1-2 месяца спустя. На место в выдаче определенного сайта через поисковые системы влияет огромное количество факторов начиная от упоминаний (количество ссылок на данный ресурс) и заканчивая собственными видеоматериалами на портале «YouTube».

\section{Сбор данных с помощью СМИ}

Данный метод позволяет отслеживать новости на определенную тематику - отраслевые, законодательные, о конкурентах (если фирма достаточно известна). К плюсам данной информации стоит отнести максимальную быстроту получения и лаконичность, что упрощает систематизацию данных. Кроме того, у большинства новостных агентств существует опция «подписка на новости», благодаря которой можно оперативно отслеживать экономические, политические и иные изменения по ключевым словам.

\section{Сбор данных с помощью блогов и социальных сетей}

Возможность находить человека с помощью социальных сетей первыми стали использовать коллекторские агентства. Для 
этого на сайтах знакомств размещались анкеты с привлекательными девушками/ молодыми людьми, от лица которых велась переписка со списком фигурантов, которые потенциально могли быть искомым должником. Целью переписки было получение местонахождения, электронной почты, телефона, что помогало оперативно находить должника.

Особенностью российских социальных сетей является то, что добиться гарантий по защите частной информации просто невозможно. «Данные, содержащиеся на социальных сетях и бесплатных страничках, по российским законам не относятся к охраняемой информации, - комментирует руководитель службы блогов компании «Суп» Антон Носик.

Помимо коллекторских агентств, данной информацией активно пользуются физические лица при знакомстве друг с другом, а также работодатели при оценке потенциальных кандидатов (особенно часто указание в резюме ссылок на собственный аккаунт в социальных сетях требуют у специалистов по продвижению сайтов и групп, реже у копирайтеров).

\section{Сбор данных,}

\section{предоставляемых контрагентом}

К данному виду информации можно отнести:

- сайт компании: домен, структура сайта, изменения, трафик, контент, стиль изложения

- наличие отзывов (на сайте компании, а также популярных форумах или блогах)

- поиск упоминаний на других сайтах (партнерские программы, отзывы в b2 b сегменте и др.)

На сайте следует обратить внимание на доменное имя (дата регистрации, на кого оформлен, есть ли сходство в доменном имени с другими крупными компаниями) и сопроводительную информацию. Получить эту информацию можно на сайтах www.nic. ru/whois или www.vline.ru.

При исследовании сайта контрагента разумно проявлять осторожность, исследовать данные в режиме «оффлайн» и по возможности исследовать инструкции системного администратора для поисковых роботов. Стоит обратить внимание на наличие/отсутствие грамматических ошибок, опечаток, миссии компании, истории развития и других информационных материалах.

На сайте www.news.netcraft.com можно изучить историю изменений программной части сервера исследуемого сайта. Анализ полученной информации позволит сделать выводы о том, как руководство компании относится к информационной составляющей своей компании, насколько современное оборудование она использует.

Также будет полезным рассмотреть трафик сайта. В России сбор информации на эту тему используется предприятиями редко, поэтому найденная информация может оказаться недостаточно корректной и применять ее нужно с осторожностью и поправками на потенциальную неточность полученных данных.

Для того, чтобы найти отзывы о компании среди тысяч блогов, форумах или персональных страниц можно воспользоваться сервисом www.blogs.yandex.ru (уместен для анализа pycскоязычного контента). Стоит иметь ввиду, что полученная информация субъективна и далеко не всегда отражает реальную ситуацию (пользователи интернета склонны с большей вероятностью распространять и обращать внимание на негативные отзывы, чем на положительные примеры).

Примеры недостаточного использования информации о контрагентах физическими и юридическими лицами 
Моченничество с анонимным посредничеством и авансовыми платежами

Контрагент: ООО «Бигбаззи», ОГРН 1107746461019

Пострадавшие: физ.лица (было куплено более 7000 купонов на сумму более 140 млн. рублей)

Причина: не был известен поставщик продукции, нарушение сроков доставки

Мотив заключения сделки: жадность, отсутствие элементарных экономических знаний

Что надо было делать: читать условия предоставления услуг «Бигбаззи», изучить существенные условия заключаемых договоров (сроки, место, поставщик и др.)

19 октября - 15 декабря

Лучшая цена: iPhone 4 S со скидкой от $51 \%$.

43199 p. $-54 \%=19990$ p. КУПИТЬ 羊

Уже купили 4422 купона

В продаже ещё 655 купонов

В октябре 2011 г. скидочный сайт BigBuzzy. ru предложил новые еще не вышедшие на российский рынок iPhone $4 \mathrm{~S}$ со скидкой в 51\%.При этом ничего не было известно ни о поставщике телефонов, ни о дате начала официальных продаж в России. Данная модель пользовалась невероятным ажиотажем, и маловероятно, что Apple могли бы выпустить новую модель со скидкой (стоимость в 43 т. устанавливалась перекупщиками, официально завезенные модели стоили бы около 35 т.). Однако акция выглядела настолько заманчивой, что в ней участвовали около 7000 человек. Для получения смартфона со скидкой требовалось заплатить полную стоимость (внести предоплату) и ждать начала поставок. Таким образом, за несколько дней BigBuzzy удалось заработать более 140 млн. рублей.
В обещанную дату поставок выдача iPhone не началась. Один за другим приходили письма с извинениями в расчете на то, что оплатившие купоны покупатели будут терпеливо ждать новые телефоны. До нового года были реализованы лишь около 500 смартфонов. По состоянию на 23.10.13 BigBuzzy убрали данную акцию из архива и вместо нее показывают фотографии тех, кто получил iPhone $4 \mathrm{~S}$ (мероприятие растянулось более чем на год, за это время стоимость телефона снизилась и итоговая скидка составила ощутимо меньше заявленных 50\%).

Сегодня в социальной сети «Вконтакте» существует несколько групп пострадавших от действий «BigBuzzy» (например, http:// vk.com/iphone4_s), где участники обмениваются опытом и рассказывают о выигранных судебных исках к купонному сайту. Про компанию ходили слухи о предстоящем банкротстве, однако по состоянию на 21.10.13 решение о ликвидации юридического лица не было принято.

\section{Создание ажиотажа вокруг собственной персоны и дезинформация}

Контрагент: Сучков Александр Вячеславович, руководитель 19 фирм, коуч

Пострадавшие: физ. лица, возможно и владельцы фирм, обратившиеся за консультациями

Причина: предоставление информации, которую сложно проверить (личная биография)

Мотив заключения сделки: восхищение, зависть, лень (желание легко и быстро заработать 1 млн. \$ и увеличить существующие объемы продаж)

Что надо было делать: искать информацию о Сучкове А. В. не только как о физ. лице, но и о его активности в составе юридических лиц 


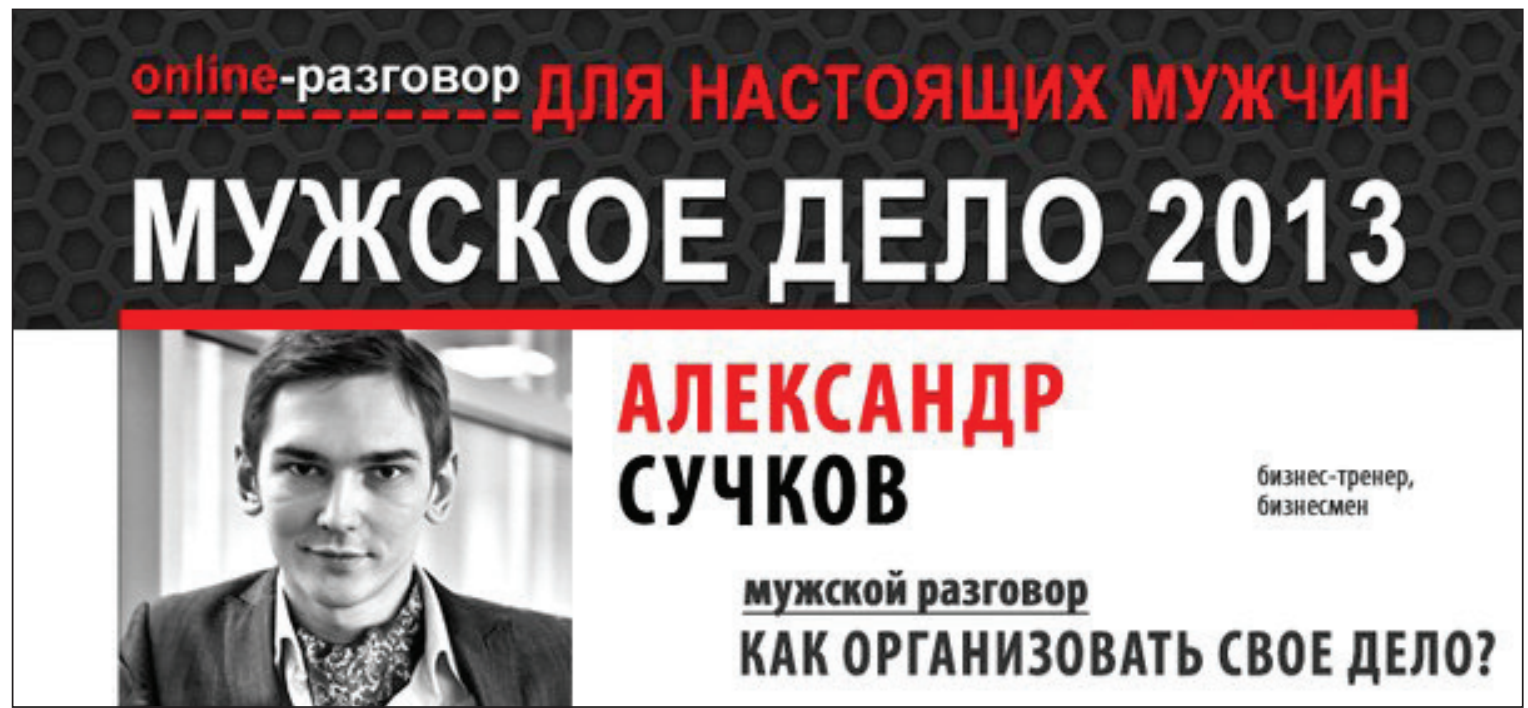

Сучков Александр Вячеславович инфобизнесмен, занимается консалтингом и параллельно ведет огромное количество проектов ${ }^{1}$. В качестве своего кумира выдвигает Остапа Бендера. Сообщает о себе следующую биографию ${ }^{2}$ :

15 лет - оказался на улице.

18 лет - свой первый крупный бизнес.

20 лет - первый миллион долларов.

22 года - президент закрытого клуба предпринимателей

23 года - стал клонировать миллионеров

27 лет (текущий возраст)

А также ${ }^{3}$ :

- Более 350 успешно реализованных бизнес-проектов, совершенно в разных областях

- Совладелец более 70 бизнесов разных сегментов

\footnotetext{
${ }^{1}$ http://vk.com/virladoфициальная страница Сучкова Александра Вячеславовича

2 По данным, указанным для проведения собственного вебинара «Двухдневный тренинг по старту бизнеса с нуля и развитию существующего от долларового миллионера»: http://ag-events.timepad.ru/event/86031/

${ }^{3}$ Оригинальная орфография и пунктуация сохранены для наглядности
} 148

Bсе права принадлежат издательству ( NOTA BENE (OOO «НБ-Медиа») www.nbpublish.com
- Успешный инвестор в области недвижимости

- Президент Хедж-Фонда им.Остапа Бендера

- Владелец контрольного пакета акций Русского Купеческого Дома

- И конечно же владелец «Института12»

На его персональном сайте рассказывается биография о непростом юношестве, полученном образовании в МГУ, а также сертификатах по сочионике и фенотипологии.

В результате проведенного анализа было обнаружено, что Сучков А. В. является руководителем 19 компаний, половина из которых уже исключена из списка действующих юридических лиц. Помимо этого, НИ ОДНА из действующих компаний не предоставила объём продаж за последний год (2012). Компании зарегистрированы в Москве, Санкт-Петербурге и Вологодской области, одна из них - некоммерческая.

Кроме того, предприниматель Сучков А. В. не является учредителем ни в одной из данных компаний, что позволяет усомниться в целях регистрации стольких предприятий ${ }^{4}$ :

\footnotetext{
${ }^{4}$ Данные и таблица взяты с сайта Национального Кредитного Бюро: http://www.creditnet.ru/nkbrelation/
} 


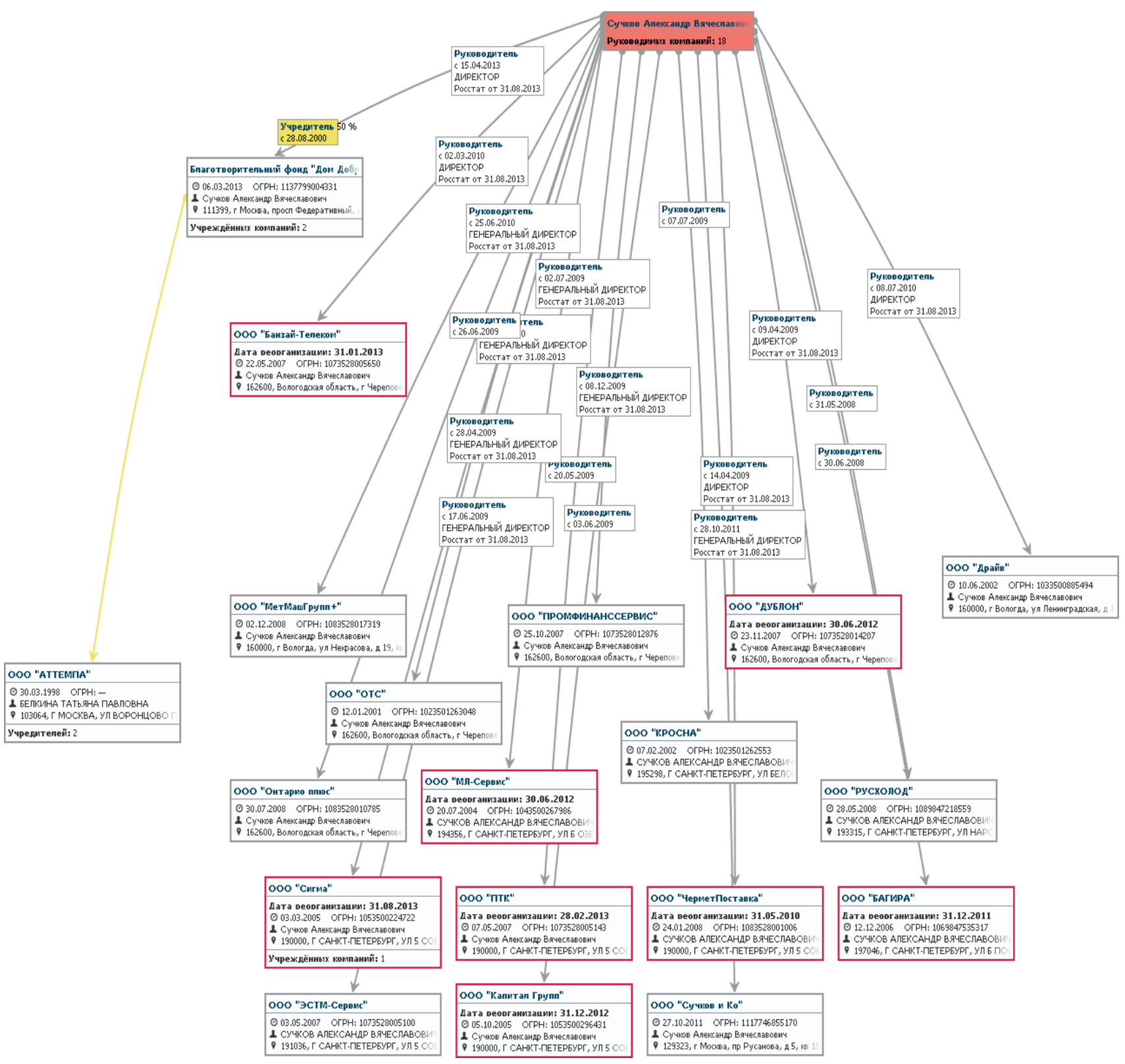

Откуда же берутся миллионы и почему ни одного финансового отчета учрежденными компаниями за 2012 г. не было сдано?

Откуда цифра в 70 бизнесов различных отраслей?

Теперь проверим действующие организации: каким же видом по ОКВЭД они занимаются. Дело в том, что если основная прибыль (более 70\%) проходит не по основному

report? node.type $=$ COMPANY\&bsn_id.equals $=9040989$ виду деятельности, то возможны штрафы. В описании к вебинару указана обучающая организация «Институт 12». Есть ли хоть одна из 9 компаний, которая могла бы теоретически заниматься оказанием образовательных услуг?

Перечислим действующие компании и их основные виды деятельности в виде таблицы (см. стр. 150).

Раздел «образование» имеет коды ОКВЭД 80.1-80.42, которые не заявлены как основ- 


\section{Национальная безопасность - №1(30)•2014}

\begin{tabular}{|c|c|c|}
\hline № & Название компании & Вид деятельности \\
\hline 1 & ООО «Кросна» & 51.70 Прочая оптовая торговля \\
\hline 2 & ООО «Драйв» & $\begin{array}{c}72 \text { Деятельность, связанная с использованием } \\
\text { вычислительной техникии информационных технологий }\end{array}$ \\
\hline 3 & OOO «OTC» & 45.4 Производство отделочных работ \\
\hline 4 & ООО «ПРОМФИНАНССЕРВИС» & 65.23.1 Капиталовложения в ценные бумаги \\
\hline 5 & ООО «ЭСТМ-Сервис» & $\begin{array}{c}51.52 \text { Оптовая торговля металлами } \\
\text { и металлическими рудами }\end{array}$ \\
\hline 6 & ООО «МетМашГрупп+» & $\begin{array}{l}51.5 \text { Оптовая торговля несельскохозяйственными } \\
\text { промежуточными продуктами, отходами и ломом }\end{array}$ \\
\hline 7 & ОоО»РУСХОЛОД» & $\begin{array}{c}51.53 \text { Оптовая торговля лесоматериалами, строительными } \\
\text { материалами и санитарно-техническим оборудованием }\end{array}$ \\
\hline 8 & ООО «Онтарио плюс» & 52.42 Розничная торговля одеждой \\
\hline 9 & ООО «Сучков и Ко» & 74.8 Предоставление различных видов услуг \\
\hline 10 & Благотворительный фонд «Дом Добрых Дел» & $\begin{array}{l}65.23 \text { Финансовое посредничество, } \\
\text { не включенное в другие группировки }\end{array}$ \\
\hline
\end{tabular}

Александр Сучков

28 февраля 2013 в 10:50

Кстати, новые пакеты под инвестирование в Хэдж-Фонд доступны, кому

интересно - звоните мне на моб.

Теперь есть и супер короткие (4 недели - 10\% - гарантия)

и подольше, до сентября (от 70 до 140\% - без гарантии)

ну и парочку средненьких.

Puc. 1 .

ные ни в одном виде деятельности. Возникает вопрос: каким образом оплачивались образовательные услуги и были ли они вообще?

При дальнейшем анализе страниц А. В. Сучкова были выявлены записи о сборе денег ${ }^{1}$ с перечислением не в Благотворительный фонд «Дом Добрых Дел», а на банковскую карточку предпринимателя. Таким образом, благополучателем платежей становится не некоммерческая организация, а физическое лицо

\footnotetext{
${ }^{1} \mathrm{http}: / /$ virlads.livejournal.com/156812.html
}

(ст. 5 Ф3 т 11 августа 1995 г. N 135-Ф3 «О благотворительной деятельности и благотворительных организациях»). В тексте статьи от 12 марта 2013 г. сообщалось:«Mbl обешуаем, что вы увидите всю собранную сумму, а так же список всех купленных на нее товаров. Так же с меня фотоотчет о том, как все прошло!», однако дальнейших записей с тегом \#Благотворительность в журнале не было.

Кроме того, Александр Сучков агитировал инвестировать в его хедж-фонды с доходностью $40 \%$ за 4 месяца и гарантированным 
возвратом средств ${ }^{1}$, а затем расширил пакет предлагаемых услуг (рис 1).

В числе плюсов инвестиционного продукта отмечались

- честность

- прозрачность

- краткосрочность

- оперативность

Заявки на участие в данном проекте предлагалось отправлять на почту до 1 февраля 2013 г., а дальше условия оплаты и получения денежных средств озвучивались по телефону. Сегодня существует закрытая группа граждан, которым Сучков А.В, должен денег (http://vk.com/club58441876, 93 человека по состоянию на 21.10.13).

К сожалению, проверить такие пункты, как «в 15 лет оказался на улице» или «куда отправились собранные средства для детей из детдома», юридически проблематично, однако качество образовательных и финансовых услуг от такого «долларового миллионера» не вызывает доверия.

\section{Заключение}

В настоящее время масштабы экономического шпионажа существенно возросли. Информация о чужих результатах научных и прикладных исследованиях позволяет сэконо- мить собственные средства, сосредоточив силы на производстве (копировании технологии) и маркетинге. Дальнейшее развитие технологий и существующие сегодня экономические предпосылки делают мониторинг информации конкурентов прибыльным бизнесом. Высокий уровень конкуренции вынуждает производителей нарушать этические и юридические нормы, поскольку потенциальная прибыль превышает риски, связанные с разоблачением.

Исходя из этого, сегодня предприятия независимо от размера должны тщательно защищать собственные коммерческие секреты и параллельно - регулярно использовать деловую разведку (самостоятельно либо с помощью привлеченных специализированных аналитических фирм).

Соревнование в технологиях приводит к тому, что производители любого товара должны заниматься сбором информации о конкурентах. Спрос на подобные услуги родил новую отрасль «информационных брокеров», которые пользуются легальными и нелегальными методами для получения нужной информации. В США она считается одной из самых быстрорастущих отраслей, а значит, в скором времени такое утверждение станет актуальным и для России, вступившей на путь развития рыночной экономики.

\section{Библиография}

1. Доронин А. И. Бизнес-разведка.- 5-е изд., перераб. и доп.- М.: Ось-89, 2010 Конвенция Совета Европы о защите физических лиц при автоматизированной обработке персональных данных

2. Коноплева И.А., Богданов И.А. Управление безопасностью и безопасность бизнеса: Учебное пособие для вузов - М.: ИНФРА-М, 2014

3. Ющук Е. Л. Интернет-разведка. Руководство к действию. М.: Вершина, 2007

4. Е. П. Губин, П. Г. Лахно. Предпринимательское право Российской Федерации: учебник 2-е изд., перераб. и доп.- М.: Норма: ИНФРА-М, 2011

\footnotetext{
${ }^{1}$ http://vk.com/virlad? w=wall3012458_4217\%2 Fall — ви-
} део Сучкова А.В. с демонстрацией графиков доходности 


\section{Национальная безопасность - №1(30)•2014}

5. Бюро Кредитных Историй // creditnet.ru

6. Леонов А., Семенова А. Напрасные слова: как виртуальные откровения пользователей Интернета рушат реальные семьи и карьеры// Газета «Новые Известия»

7. Федеральная налоговая служба // egrul.nalog.ru

\section{References (transliterated)}

1. Doronin A. I. Biznes-razvedka.-5-e izd., pererab. i dop.-M.: Os'-89, 2010 Konventsiya Soveta Evropy o zashchite fizicheskikh lits pri avtomatizirovannoi obrabotke personal'nykh dannykh

2. Konopleva I. A., Bogdanov I. A. Upravlenie bezopasnost'yu i bezopasnost» biznesa: Uchebnoe posobie dlya vuzov - M.: INFRA-M, 2014

3. Yushchuk E. L. Internet-razvedka. Rukovodstvo k deistviyu. M.: Vershina, 2007

4. E. P. Gubin, P. G. Lakhno. Predprinimatel'skoe pravo Rossiiskoi Federatsii: uchebnik - 2-e izd., pererab. i dop.-M.: Norma: INFRA-M, 2011

5. Byuro Kreditnykh Istorii // creditnet.ru

6. Leonov A., Semenova A. Naprasnye slova: kak virtual'nye otkroveniya pol'zovatelei Interneta rushat real'nye sem'i i kar'ery// Gazeta «Novye Izvestiya»

7. Federal'naya nalogovaya sluzhba // egrul.nalog.ru 